\title{
Land Use Sector Involvement in Mitigation Policies Across Carbon Markets
}

\author{
Severino Romano, Simone Targetti Ferri, Gennaro Ventura, Francesco Di \\ Napoli, and Mario Cozzi
}

\begin{abstract}
Different local and international experiences show that the agroforestry sector can be fully included in the global warming mitigation strategies and in the market mechanisms that may have environmental and socioeconomic benefits. At present, however, the primary sector plays only a minor role in mitigation policies within the UNFCCC and under Kyoto's Protocol, due to problems and difficulties related to emission/absorption accounting models and monitoring and standardisation systems. If, on one hand, the progress in science has enabled to overcome accountingrelated problems, on the other, there are no adequate mechanisms to encourage and remunerate the primary sector's efforts. More specifically, if the primary sector is considered as a source of emissions, it should also be recognised that it has beneficial impacts, notably in economic terms, as carbon sink. Therefore, the definition of clear and internationally shared rules might increase the carbon friendly initiatives and help reduce greenhouse gas emissions. This article is focused on the international experiences that have concerned the primary sector and is intended to supply researchers and policymakers with suggestions and recommendations for implementing local market practices related to carbon credits.
\end{abstract}

\section{Introduction}

The inclusion of the agricultural and forestry sector in the global warming mitigation strategies has not been clearly and definitely implemented yet. As a matter of fact, if the primary sector accounts for over $30 \%$ of greenhouse gas emissions (FAO 2003), on the other hand, it has a great potential absorptive capacity (Galik et al. 2009; Gorte and Ramseur 2010). Agricultural and forestry activities actually play a twofold role in climate changes, since they suffer from their effects, while still contributing, either positively or negatively, to emissions (Pettenella et al. 2006).

\footnotetext{
S. Romano • S.T. Ferri • G. Ventura • F. Di Napoli • M. Cozzi $(\bowtie)$

School of Agricultural Sciences, Forestry, Food and Environment - SAFE, viale dell'Ateneo

Lucano 10, 85100 Potenza, Italy

e-mail: severino.romano@unibas.it; mario.cozzi@unibas.it
} 
Recent studies have highlighted that forests have the highest absorption capacity of greenhouse gases (GHGs; Beer et al. 2010; Canadell et al 2007). The primary sector's capacity to act as carbon sink is limited in the space and over time and might be strengthened by specific management measures aimed at increasing the carbon sink potential and reducing the release of GHGs (Houghton 2003; Pacala and Socolow 2004; Ciccarese and Pettenella 2005; Canadell and Raupach 2008; Sohngen 2009). The main measures aimed at increasing the absorption capacity include:

1. Forestation and reforestation practices and the reduction of deforestation

2. Reducing forest degradation by improving forest stand quality

3. The sustainable use of fertilisers and other chemicals in agricultural practices

4. Maintaining carbon stocks within ecosystems through the implementation of sustainable forest management (SFM techniques)

5. The use of biomasses and wood material as substitutes for fossil fuel-derived products

The need to introduce appropriate procedures in climate change mitigation strategies has actually been debated in recent years. In the new Common Agricultural Policy (CAP), the struggle against climate changes and the primary sector's contribution to a low carbon economy have actually been included among the European objectives. Despite the efforts made, in the 2008-2012 Kyoto's Protocol (KP) first planning phase, the carbon credits generated by LULUCF (Land Use, Land Use Change and Forestry) activities were not included in the EU Emissions Trading System (EU-ETS), which is the largest regional market of carbon credits currently working at the world level (Hamilton et al. 2011; Bonomi et al. 2009). This exclusion means that the Removal Units (RMUs) cannot be converted into European Union Allowances (EUAs) so they are not tradeable in the European market. With this in mind, this work is intended to review the role of the primary sector in the struggle against climate changes based on the analysis of the main markets involved and of the currently available accounting methods, so as to highlight their strengths and weaknesses. Some suggestions and reflections are then proposed to implement an appropriate model of local compensation voluntary market that can promote local development and generate economic and environmental benefits to the actors concerned, in terms of mitigation/reduction of climate altering gas emissions.

\section{The Primary Sector in the International Negotiation}

The United Nations Framework Convention on Climate Change (UNFCCC), the first legal international tool to contrast climate changes, ratified the need to initiate a global complex action in favour of the environment and sustainable development. In fact, in compliance with the three main pillars mentioned in the Convention, equity between generations, common but differentiated responsibility and 
precaution, the UNFCCC invited the member States to monitor the national GHG flows grouped by sectors and to communicate regularly their inventories and the planned reduction measures. Based on the classification drawn up by the Organisation for Economic Co-operation and Development (OECD), the member States were subdivided into three groups: Annex I countries should take the lead in modifying the trends in greenhouse gas emissions, Annex 2 countries are required to assist financially nondeveloped countries and non-Annex I countries have no reduction obligation. The proposals developed during the Heart Summit of 1992 were implemented only in 1997 during Kyoto's 3rd Conference of parties (COP-3). During the COP-third session, most national governments from all world regions decided to approve "Kyoto's Protocol" (signed by 176 countries, 38 of which have binding targets), to enforce compliance with the commitments made at Rio. The protocol is the implementation tool of the Framework Convention on Climate Change and defines legally binding limits for greenhouse gas emissions in industrialised countries. The treaty imposed on Annex I countries to account their GHG flows by sector and to reduce pollutant emissions by at least $8 \%$ compared to 1990, which was selected as baseline year. As to the accounting methodology, the applied mechanisms include the gross-net accounting, ${ }^{1}$ adopted for some activities, such as forest management, and the net-net accounting ${ }^{2}$ for reforestation and the management of cultivated fields and pastures.

\section{Overview of Carbon Credit Markets}

KP provides some actions to be taken by industrialised countries for the reduction of their emissions. These actions are categorised as domestic or national actions and international actions or flexible mechanism. The former are targeted towards the reduction of energy consumption in all economic sectors, whereas the second group includes actions to be implemented through cooperation among developed countries and between them and developing countries. Among flexible mechanisms, a major role is played by Emission Trading (ET), which has enabled the setting up of the so-called carbon credit markets, which may be either regulated or voluntary (Torres et al. 2015; Linacre et al. 2011; Pirard 2012).

The differences encountered in the two markets are quite significant; regulated (or mandatory) markets are actually identified by their regular functioning, based on rules established by institutional bodies that ensure transparency requirements and the obligation to provide information on prices and the traded volumes. This type of

\footnotetext{
${ }^{1}$ The gross-net accounting includes only the carbon stock variations due to the differences between emissions and removals in the commitment period, without comparison to the stock variations in the reference year (baseline).

${ }^{2}$ The net-net accounting measures the carbon flux variations-observed in the commitment period-compared to the reference year (baseline).
} 
market is accessible — upon specific request - to the big industrial groups, submitted to regulatory emission limits and obliged to comply with the trading system. At the international level, there are 15 regulated markets based on the Emission Trading System (ETS) and characterised by a cap and trade ${ }^{3}$ (IETA 2014) accounting system. Voluntary markets instead are not based on a system of consistent rules defined by authoritative bodies; this makes possible non standardized contracts both for the amounts and the deadlines. These markets are based on a system of offsets ${ }^{4}$ that can link directly both market actors, i.e. the parties interested to implement GHG mitigation projects that represent the supply side and the parties intended to compensate for part of their emissions that instead represent the demand side.

\section{Analysis of the Main International Markets and the Inclusion of the Agroforestry Sector}

\subsection{International Voluntary Markets: The Verified Carbon Standard}

The Verified Carbon Standard (VCS) is one of the leading programmes to reduce GHGs in the voluntary market, and with regard to Agriculture, Forestry and Other Land Use (AFOLU), it is used to check and certify the credits generated by land use improvement projects. Over the last few years, many accounting models, often differentiated by geographical areas, have been proposed within the VCS to take into account the local and/or sectoral peculiarities.

In dimensional terms, the VCS does not set any limitation, in terms of project size, while classifying projects in three main categories:

1. Micro projects with an absorption potential below $5,000 \mathrm{t} \mathrm{CO}_{2} /$ year

2. Projects with an absorption potential ranging between 5,000 and 1 million $\mathrm{CO}_{2} /$ year

3. Macroprojects with an absorption potential above 1 million $\mathrm{CO}_{2} /$ year

In operational terms, the VCS system involves different information about the project for the purpose of monitoring and understanding its positive and negative impacts, in terms of potential production of $\mathrm{CO}_{2}$, competition with other chains related to the primary sector, economic sustainability, scope (whether public or private), causes of failure, etc. As to the criterion of additionality, meant as

\footnotetext{
${ }^{3}$ The cap and trade system involves defining a maximum limit (cap) of emissions, subdivided into a given number of licences that are distributed among participants, with reference to a limited time period. Permits may be freely traded among the participants in the trade market, but at the deadline of the reference period, each should return as many permits as those corresponding to its actual emissions.

${ }^{4}$ Mechanism involving the purchase of carbon credits to offset an emission made elsewhere.
} 
reduction of any extra emission produced in the absence of the certified project activity, the standard refers to what is provided for in the Clean Development Mechanism (CDM) (Montini 2008), with the additional possibility to carry out three types of test: the project test, the performance test and the technology test. The determination of the baseline is based on the methodologies approved for the CDM, whereas the leakage factor, meant as the increase in the emissions in areas beyond the project boundaries, is calculated in advance by analysing carefully the area at risk and indicating a default value that ranges, depending on the risk, between 10 and $70 \%$.

To ensure effective GHG absorption rates, the VCS-certified projects are submitted to an initial checking and a periodical control every 5 years based on ISO 14064-2:2006 principles.

The VCS has been the main market platform, in terms of credits traded at purchase prices of $7 \$ / \mathrm{t} \mathrm{CO}_{2}$. Most projects have concerned the mechanism of reducing emissions from deforestation and forest degradation (REDD) followed by afforestation/reforestation $(\mathrm{A} / \mathrm{R})$ and sustainable forest management.

\subsection{The American Carbon Registry Standard (ACR)}

The ACR was founded in 1996 as the first voluntary GHG registry in the world. In relation to the LULUCF sector, the ACR includes methodologies related to $\mathrm{A} / \mathrm{R}$, REDD and Improvement of Forest Management (IFM). The innovations of the ACR consist in the introduction of a methodology to restore wetlands, a REDD methodology and a methodology for $\mathrm{N} 2 \mathrm{O}$ in agriculture, contained in the ACR guidelines enacted in 2012. The ACR standard sets limits on the initial date of projects that should not have started before November 1, 1997. For the projects complying with the ACR, it is necessary to provide an accurate certification of the right of ownership of the estates concerned in compliance with the local existing regulations.

As for the criterion of additionality, the ACR requires for each project a performance testing or alternatively the fulfilment of three types of additionality criteria:

1. Regulatory/legal requirements

2. Innovative requirements of the common project practices

3. Institutional, financial and technical requirements

The ACR platform provides, the same as the VCS, periodical checking every 5 years in order to test GHG absorptions and all risks connected with the project. The crediting period, provided for by the ACR standard, is 20 years for $\mathrm{A} / \mathrm{R}$ activities and 10 years for REDD and IFM projects.

Due to its stringent procedures, this year the ACR has allowed higher credit prices than the other voluntary platforms with values ranging between 8 and $9 \$ /$ $\mathrm{t} \mathrm{CO}_{2}$ especially for $\mathrm{A} / \mathrm{R}$ projects. 


\subsection{Regional Carbon Market}

\subsubsection{The European Trading Systems (EU-ETS)}

The ETS was introduced in 2005 by the EC Directive 2003/87 amended by the EC Directive Linking 2009/29 and includes both cap and trade and offsetting systems that allow parties to buy and sell EUA emission permits and carbon reduction credits (offsets) in order to comply with the pre-established reduction objectives. As a matter of fact, the EU-ETS obliges some sectors to limit their emissions of $\mathrm{GHG}^{5}$ and creates a real credit market in which the supply is represented by those who can reduce their emissions above the established limits, thus generating credits, whereas the demand side is represented by those who do not comply with the reduction constraints and are obliged to address to the market for fulfilling their obligations.

The COP-17, held in Durban in 2011, has boosted the agreements designed to contrast climate changes; the new accounting rules resulting from the international meeting have actually driven the European Parliament and Council to develop a proposal concerning the action plans on the greenhouse gas emission and absorption associated with the LULUCF activities. Besides some actions provided for in the project monitoring phase, the following was proposed - the voluntary supervision of emissions and absorption due to revegetation activities, drainage and rewetting of wetlands and the obligation, since January 1, 2013 to December 31,2020 , to report the emissions and absorption due to man-made activities of afforestation, reforestation and deforestation:

- Forest management

- Management of cultivated lands and pastures

Following on the European Parliament and Council's approval, the decision was enforced on July 8, 2013 (Decision 529/2013/EU of the European Parliament and of the Council) and constrained the member States-starting from 2014-to collect and communicate all information on the LULUCF implemented policies, including the historical trends and implemented actions to increase carbon sinks and reduce the emissions produced by the activities connected with the primary sector. Although no reduction target was established for single member States, the Decision 529/2013 has marked a new step for the inclusion of the LULUCF sector in the mechanisms targeted to contrast climate changes at the European level.

\footnotetext{
${ }^{5}$ The system concerns carbon dioxide $\left(\mathrm{CO}_{2}\right)$ emissions for thermoelectric and industrial plants in the field of energy and manufacturing production (energy activities, metal production and processing, concrete, ceramic and bricks, glass, paper) and air operators; since 2012 the system has also been enlarged to the operators of the air sector and, since 2013 it has been further extended to the activities for the production of aluminium, quicklime, nitric acid, hydrogen, sodium carbonate and bicarbonate and to the plants involved in $\mathrm{CO}_{2}$ capture, transportation and storage.
} 


\subsubsection{The Chicago Climate Exchange}

The Chicago Climate Exchange (CCX) is an exchange platform created in 2003 by private citizens. To ensure the full transparency of operations and the compliance with rules, an independent inspection authority, the Financial Industry Regulatory Authority (FINRA), was established. The main tasks of the FINRA were the spread of information and guidelines relating the operation of the market, the development and updating of the baselines and the activity of checking and annual certification of the offsets programme. Because it does not operate for public purposes but according to merely private objectives, such as the adoption of simple and costeffective measures for the calculation of the baselines and for the estimate of GHG emissions, the system has lost, over time, its transparency, thus discouraging those interested to join the CCX that has officially ceased to exist in 2011 but has still operated in the markets over the counter ${ }^{6}$ (OTC).

The objective of the CCX was to regulate the trade of GHG emission quotas indicated by the Intergovernmental Panel on Climate Change (IPCC 2006) as extremely dangerous to the environment. Public and private operators could join this market, on a voluntary basis, through a legally constraining agreement between the same operators. The CCX provided for a cap and trade system associated with an offsetting mechanism that assessed the production of credits derived from the activities related to the management of agricultural, forest and pasture areas, based on the compliance with the principles and constraints imposed by the specifically created standard. In fact, the estimates were based on the applied practices rather than on the actually measured effects induced by the project.

As to the type of project, the CCX did not indicate any limitations in terms of eligibility or project size; the actual unique constraint was the project start date that should not have been before January 1, 1999 (1990 for forestry). The duration of the investment was 15 years for forest management projects.

Moreover, the CCX required two types of test, related to regulation and common practices, to satisfy the additionality criteria, and a storage quota, not below $20 \%$ of the total credits generated by the project to satisfy the permanence criteria.

\subsection{The National Carbon Markets}

A voluntary national market often requires the involvement of the central government in bearing the start up and running costs and ensuring the initial quantity of demand. The participation and involvement of national institutions in a voluntary market also facilitates the access to funding and aids and also increases the economic and collaboration opportunities with research bodies, enabling the development of a local standard system more consistent with the real conditions of the

\footnotetext{
${ }^{6}$ The OTC markets are over the counter.
} 
reference area. One of the advantages of this type of market is the possibility to set the prices on a local basis, i.e. based on the local demand and supply levels. The peculiarity of the local voluntary market is actually the existing proximity between the seller, the buyer and the mediator. These three categories, appropriately interrelated within an environmental, social and economic approach, may originate a transparent, functional and sustainable system. At the local level, it is also easier to include the primary sector in the market mechanisms, thanks to the possibility to elaborate ad hoc methodologies closely related to local dynamics. Lastly, by restricting the scope of the market, there are greater aggregation possibilities in terms of project proposals. This enables the reduction of transaction costs as well as the development of more coordinated and sustainable strategies, preventing sporadic and isolated actions.

Another important element of voluntary markets is the possibility of setting up an actual registry of credits where to record all the credits generated by voluntary actions and prevent the problem of double accounting.

\subsubsection{The Carbomark Project and the Carbon Monitoring Group}

In Italy, the difficulties related to the methods for the recognition and accounting of the credits derived from the forestry sector are particularly accentuated as compared to other countries, due to the impossibility for forest owners to have access to the carbon market. As a matter of fact, the carbon stored by all Italian woods (both public and private) has been converted into the corresponding RMU credits by the National Registry of Agroforestry Carbon Sinks (INFC), which are utilised by the national government to fulfil its obligations to reduce emissions, without paying any compensation to forest owners, thus confining the sink function to a mere externality of the forestry production cycle (Alisciani et al. 2011). For Italy, the accounting of RMUs prevents forest owners from having access even to voluntary markets, due to the double accounting, contrary to other European countries, such as France, for instance, where the State has taken well-defined regulatory measures to distinguish the two markets: in fact, in France, the State has allocated part of its stocks of Assigned Amount Units (AAU) to emit Emission Reduction Units (ERUs) to the developers of GHG reduction projects, thus producing an economic return derived from the sale of credits. Despite the difficulties pointed out for forestry, some initiatives have been developed in Italy within the voluntary market to promote actions aimed at reducing GHGs. From a scientific point of view, the Carbon Monitoring Group ${ }^{7}$ has worked out a Forest Carbon Code with a view to stimulating low carbon economy, by facilitating private and public investments in

\footnotetext{
${ }^{7}$ The Carbon Monitoring Group stems from the need to strengthen and make more transparent the national voluntary market of carbon credits. It was established by the Osservatorio Forestale dell'Istituto Nazionale di Economia Agraria in collaboration with the Dipartimento TeSAF of Padua University, the Dipartimento DiBAF of Tuscia University and the Compagnia delle Foreste.
} 
forest and farmland management, the afforestation of new areas and the improvement of green systems in agricultural and urban systems in Italy. In line with the existing experiences in Europe, the Code actually intends to provide landowners (either public or private) with guidelines for the sustainable management of green areas that can generate carbon credits to be included in the national and international voluntary market.

From a practical and merely local point of view, the Carbomark project was implemented some years ago in order to promote a voluntary local market of carbon credits operating on a wide range of agroforestry activities, such as forest management, wood products, urban forestation and biochar. The Carbomark project is based on the matching of demand from the private sector and supply, represented by forest owners and public or private local bodies that sometimes take measures directed to carbon sequestration. As for the double accounting, considering the specific legal condition existing in Italy, it has been established that the forest inventories defined under Kyoto's Protocol should be considered business as usual. Therefore, the additional quota obtained by the forest owners who adopt sustainable and certified management systems for a given time period (usually 20 years) is not accounted at the national level and is thus tradeable within a voluntary market.

The Carbomark market was enforced some years ago and has recorded credit selling prices between 4 and $80 €$. The observed price range is influenced by the type of implemented projects.

\section{The Inclusion of Agroforestry in Mitigation Policies: Some Remarks}

The major role of the primary sector in the fight against climate changes was known since the implementation of KP. This is demonstrated by the fact that PK provided for different activities specifically mentioned in arts 3.3 and 3.4 concerning the LULUCF activities. Despite this, it is only recently that the EU has invited the member States to monitor very carefully the GHG flows related to the primary sector and to identify all the activities aimed at increasing the role of carbon sinks of agricultural and forest lands.

The primary sector may influence significantly the absorption and storage capacity of large amounts of carbon. To that effect, it is worthy underlining that the LULUCF sector is considered in the European policies to contrast climate changes just because it is the unique natural sector that can actually store significant amounts of $\mathrm{CO}_{2}$. Besides being directly one of the main carbon sinks, the primary sector includes different associated subsectors, like that of agroforestry biomasses, and contributes indirectly to the reduction and absorption of GHGs through the production of clean energy produced from renewable sources.

The main reason for including the LULUCF sector in the strategies to contrast climate change is the possibility to measure and monitor more accurately, as 
compared to the past, the emissions and absorption of GHGs. The science achievements in this area enable, under the existing conditions, to assess more accurately the magnitude of emissions/absorption with significant future repercussions both at the European and international level. To this end, the methodology for calculating the baselines, the tests aimed at ensuring the criterion of additionality and the monitoring and checking systems, combined with the strategies implemented to limit the inefficiencies resulting from temporary absorption, have made the VCS and ACR the most largely used basic models for the implementation of new market mechanisms on the international scale.

Among the various types of offset projects, afforestation, reforestation, the sustainable forest management and the reduction of forest degradation (as for the forest sector), pasture and farmland management (for the agricultural sector) are by now well-established techniques that may be included in any market mechanism.

Besides Kyoto's principles and the cap and trade system that does not promote agroforestry credits, Italy faces a quite complicated legal situation. Despite this, the huge resources linked to the national land area have induced to elaborate the Carbon Code to encourage landowners to take soil management measures and increase GHG absorption, thus reducing the emissions into the atmosphere. The experiences implemented across the national area, such as the Carbomark project, have yielded good results and outlined new strategies to contrast climate changes. This confirms the importance of woody products in carbon storage, in line with the principle of absorption permanence, in addition to the identification of innovative mechanisms for the solution of the problems concerning double accounting. Other experiences conducted at the international level, such as in New Zealand, have demonstrated that forest owners' participation in the carbon credit market ensures better results, in terms of reduction of carbon emissions, and generates new income resources that could be reinvested in the agricultural-forest sector, besides many positive externalities associated with the forestation of new areas and the management of the existing ones (employment, tourism, bioenergy, etc.).

From an economic point of view, the prices observed in the examined markets show heterogeneous levels due to internal and external market variables that differ according to the type of project, geographical reference area, actors involved, etc. The mean prices observed in the examined markets actually point out the need for measures and actions to be taken by public bodies to ensure both the market transparency and the stability and increase in prices with a view to including the primary sector in climate change mitigation policies.

\section{Conclusions}

This article is intended to provide some suggestions for the implementation of a voluntary local market model through the involvement of the agricultural and forestry sectors. Over the last few years, the scientific community has introduced new accounting methodologies and upgrade old standards to improve the 
procedures for calculating the GHG absorption related to the primary sector. As a matter of fact, despite the sink role of the primary sector, notably of forestry, this is not yet recognised as being eligible as the main tool to contrast climate change.

The full awareness of the general public on this problem and the increasingly targeted experiments are showing the positive effects obtained through the win-win collaboration between the public-private sector and the world of research. One of them is the cut of transaction costs through the development of transparent and accurate standardised models.

The new market experiences should be based on what has been actually achieved, showing at the same time great adaptation and flexibility capacity, with a view to minimising the risks and errors made so far. With this in mind, the implementation of a local voluntary market of carbon credits could contribute to reduce the associated risks, by testing new methodologies and improving the governance and the awareness of all actors involved. New offset mechanisms shall ensure increasing certainty on the GHG stored by the primary sector. The economic benefits to the private and public sectors should not be considered as being independent and exclusive but quite exhaustive and comprehensive. The environmental benefits, the reduction of degradation of natural resources and the development of an environmental awareness in the community should be viewed as primary mitigation elements both for developed and developing countries, with a view to putting a stop to climate change.

Open Access This chapter is distributed under the terms of the Creative Commons Attribution Noncommercial License, which permits any noncommercial use, distribution, and reproduction in any medium, provided the original author(s) and source are credited.

\section{References}

Alisciani F, Carbone F, Perugini L (2011) Criticità e problematiche nella prospettiva post-2012 per la partecipazione del settore forestale all'eventuale mercato nazionale dei crediti di carbonio. Forest@8:149-161

Beer C, Reichstein M, Tomelleri E, Ciais P, Jung M, Carvalhais N, Rödenbeck C, Arain MA, Baldocchi M, Bonan GB, Bondeau A, Cescatti A, Lasslop G, Lindroth A, Lomas M, Luyssaert S, Margolis H, Oleson KW, Roupsard O, Veenendaal E, Viovy N, Williams C, Woodward FI, Papale D (2010) Terrestrial gross carbon dioxide uptake: global distribution and covariation with climate. Science 329:834-838. doi:10.1126/science.1184984

Bonomi A, Droghei G, Lumicisi A (2009) Lo schema EU-ETS ed i crediti forestali: analisi di possibili scenari per il periodo 2013-2020. Forest@ 6:349-356

Canadell J, Raupach M (2008) Managing forests for climate change. Mitig Sci 320:1456

Canadell JG, Le Quéré C, Raupach MR, Field CB, Buitenhuis ET, Ciais P, Conway TJ, Gillett NP, Houghton RA, Marland G (2007) Contributions to accelerating atmospheric $\mathrm{CO}_{2}$ growth from economic activity, carbon intensity, and efficiency of natural sinks. PNAS 104:18866-18870. doi:10.1073pnas.0702737104

Ciccarese S, Pettenella D (2005) Il Protocollo di Kyoto. Quali possibilità per i gestori delle foreste italiane nel mercato delle quote? Sherwood 108:5-9 
Food and Agriculture Organization (2003) World agriculture: towards 2015-2030. An FAO Perspective, Rome

Galik C, Mobley M, Richter D (2009) A virtual "field test" of forest management carbon offset protocols: the influence of accounting. Mitig Adapt Strat Glob Chang 14:677-690

Gorte R, Ramseur J (2010) Forest carbon markets: potential and drawbacks. CRS report for congress. Congressional Research Service. Report 7-5700. www.crs.gov. Accessed 25 Sept 2014

Hamilton K, Peters-Stanley M, Marcello T, Sjardin M (2011) Back to the future. State of the voluntary Carbon Markets. Ecosystem Marketplace and Bloom-berg New Energy Finance. http://www.forest-trends.org/documents/files/doc_2828.pdf. Accessed 17 Dec 2014

Houghton RA (2003) Why are estimates of the terrestrial carbon balance so different? Glob Chang Biol 9:500-509. doi:10.1046/j.1365-2486.2003.00620.x

IETA (2014) http://www.ieta.org/worldscarbonmarkets. Accessed 14 Nov 2014

IPCC (2006) Guidelines for national greenhouse gas inventories. IGES, Hayama, Kanagawa

Linacre N, Kossoy A, Ambrosi P (2011) State and trends of the carbon market 2011. The World Bank, Washington

Montini M (ed) (2008) Il Protocollo di Kyoto e il clean development mechanism: aspetti giuridici e istituzionali-L'esperienza nei Balcani. Giuffrè editore, Milano

Pacala S, Socolow R (2004) Stabilization wedges: solving the climate problem for the next 50 years with current technologies. Science 305:968-972

Pettenella D, Zanchi G, Ciccarese L (2006) Il settore primario e la riduzione delle emissioni di gas ad effetto serra. Tra strumenti diretti di compensazione e politiche generiche di sostegno del settore Pigra 3:27-48

Pirard R (2012) Market-based instruments for biodiversity and ecosystem services: a lexicon. Environ Sci Policy 19-20:59-68

Sohngen B (2009) An analysis of forest carbon sequestration as a response to climate change. Copenhagen Consensus on Climate. http://aede.osu.edu/sites/drupal-aede.web/files/AP_For estry_Sohngen_v_2_0.pdf. Accessed 15 Oct 2014

Torres AB, MacMillan DC, Skutsch M, Lovett JC (2015) "Yes in my backyard": spatial differences in the valuation of forest services and local co-benefits for carbon markets in México. Ecol Econ 109:130-141 